\title{
IMPROVING CANCER SURVIVORSHIPS: TARGETING PHYSICAL ACTIVITY AND INACTIVITY AT TEACHABLE MOMENTS
}

\author{
Loh SY, Chew SL \\ Dept of Rehabilitation, Faculty of Medicine, University of Malaya, Kuala Lumpur \\ Correspondence: \\ Loh Siew Yim \\ Dept of Rehabilitation, Faculty of Medicine, \\ University of Malaya, 50603 Kuala Lumpur. \\ Email: syloh@um.edu.my
}

\begin{abstract}
This article presents a brief overview on the importance of adopting healthy behavior during and after the completion of primary cancer treatment. Increasing evidences are advocating physical activity engagement in cancer survivors due to its convincing beneficial outcomes. Today, outcomes from numerous trials confirmed the need to examine beyond physical activity engagement, into physical inactivity as an independent factor for cancer recurrences. Reducing cancer-risk related behaviors via increase physical activity and reduce inactivity is now receiving much attention in the field of cancer survivorship. Both realms of activity and inactivity are now acknowledged as influential independent factors contributing to better care in the field of cancer survivorship.
\end{abstract}

Keywords: cancer survivorship, physical activity, lifestyle redesign, occupational therapy

\section{Introduction}

The National Cancer Institute Office of Cancer Survivorship in America defines a cancer 'survivor' as anyone diagnosed with cancer, from the time of diagnosis to the end of life (1). Two factors have contributed to the steep rise of cancer survivors:

i) advanced cancer treatment and

ii) an aging population $(2,3)$.

Cancer treatments are often invasive and prolonged with unique psychological, physical, social and existential impact upon survivors (4). As breast cancer now takes a form of chronic disease (5), greater efforts are needed to ensure sustainable and relevant health-promoting programs for cancer control. Fortunately, genetic defects play its role in only five to 10 percents of all cancer cases, whereas the remaining 90 to 95 percents are rooted in the environment and lifestyle factor matrices (6). It is also important to state that not all sequela from cancer are negative as survivors will attest that a cancer diagnosis also brings out the positive feelings in them. The sequela of cancer ranges from one end of the continuum to the other end, i.e. from positive feelings of surviving (I am thankful to be alive, each day is a bonus, etc) to negative consequences (constantly living in fear recurrence, facing long term side effects, etc) as expressed by cancer survivors. In the words of a cancer patient before he succumbed to pancreatic cancer at the age of 49 yrs old -

'If God would give him another chance, he will lead a less sedentary and a healthier life'.
This expression reflects the opportunity which cancer researchers have termed as, the 'teachable moment' i.e. when survivors can be challenged and are more willing to accept ideas of positive healthy behavioral changes (7). However, more research is needed to uncover with clarity if a "teachable moment" occurs shortly after the cancer diagnosis, during cancer treatment, or sometime after treatment has been completed, or if it varies from individual to individual.

With more cancer patients surviving more than 5 years beyond diagnosis, the focus from acute care to managing the long-term health consequences of cancer must be shifted accordingly. Having a longer, indefinite period to live, cancer survivors are faced with the vast array of aftereffect of treatment. Table 1 highlights some effects that may possibly be ameliorated with physical activity intervention, and where greater support to move on to live healthily can only bring positive impact into their remaining lives. However, for decades, host factors such as weight and physical activity in the overall treatment of breast cancer patients have been disregarded until recently (8), despite the identification of World Health Organization (WHO) that physical activity (PA) is among the nine modifiable risk factor for cancer (9). The aim of this paper is to present a brief overview of the role of physical activity and inactivity as a potential influential factor in improving the quantity and quality of life of cancer survivors. The review also highlights the health behavior recommendations for cancer survivors outlined by an American Cancer Society expert panel. 
Table 1: $\quad$ Common side effects of cancer treatment (10)

\begin{tabular}{|c|c|c|}
\hline Surgery & \multicolumn{2}{|c|}{$\begin{array}{l}\text { - 'Pulling' sensation over the scar } \\
\text { - Scar contracture } \\
\text { Paraesthesia in the axilla and medial upper arm from the necessary dissection of the intercostal } \\
\text { brachial nerve at the time of an axillary clearance } \\
\text { - } \quad \text { Lymphoedema } \\
\text { Physical imbalance and difficulties with muscular neck pain due to breast tissue loss (usually only a } \\
\text { problem for women with larger breasts) } \\
\text { - Intermittent fleeting, jabbing neurological pains in the breast } \\
\text { Intermittent pain in the upper arm on the side of an axillary clearance (typically settles over 3-6 } \\
\text { months) }\end{array}$} \\
\hline Radiotherapy & \multicolumn{2}{|c|}{$\begin{array}{l}\text { - } \quad \text { Breast oedema and tenderness } \\
\text { - } \quad \text { Hyperpigmentation in the first year } \\
\text { - } \quad \text { Might evolve to increased density of the breast tissue } \\
\text { - } \quad \text { In-field telangiectasia (particularly in the inframammary region and the tumor bed RT 'boost' area) } \\
\text { - Small decrease in the size of the residual breast tissue may occur }\end{array}$} \\
\hline Chemotherapy & \multicolumn{2}{|c|}{$\begin{array}{ll}\text { - } & \text { Tiredness/fatigue } \\
\text { - } & \text { Hair loss } \\
\text { - } & \text { Bitter taste in mouth is unlikely to linger for more than a few weeks after chemotherapy } \\
\text { - } & \text { Peripheral neuropathy may persist }\end{array}$} \\
\hline Hormonal therapy & $\begin{array}{ll}\text { - } & \text { Tamoxifen } \\
\text { - } & \text { Tet flushes } \\
\text { - } & \text { Gastrointestinal upset } \\
\text { - } & \text { Vaginal dryness and discharge } \\
\text { - } & \text { Decreased libido } \\
\text { - } & \text { Abnormal vaginal bleeding endometrial carcinoma } \\
& \text { and DVTs are rare }\end{array}$ & $\begin{array}{l}\text { Aromatase inhibitors (Al) } \\
\text { - } \quad \text { Musculoskeletal pain (can be severe, } \\
\text { requiring Al treatment to cease) } \\
\text { - } \quad \text { Oaginal dryness } \\
\text { - Osteoporosis }\end{array}$ \\
\hline
\end{tabular}

\section{Physical activity during cancer survivorship}

We searched MEDLINE, EMBASE, CINAHL, Web of Knowledge, there were a total of 25 systematic reviews and meta-analysis conducted from the year of 2006 to 2011, using the key searching word, 'physical activity', 'cancer', 'systematic review', 'meta-analysis'. Cancer survivors face a range of chronic conditions with functional declines (11, 12) and they are presented with a real threat of secondary cancer (13), with many unmet needs (14). Cancer survivors often are doubtful if exercises are safe during and even after treatment. Is physical activity effective for people who are already weak from cancer treatment? Over two decades of research have revealed that breast cancer patients (and colon, prostate, hematological malignancies) $(15,16)$ can gain from physical activity programs (17). There is now convincing evidence that post-diagnosis physical activity reduces the risk of cancer recurrence, and other chronic condition. It also contributes to longer survivorship period - especially for breast, colorectal and cervix cancer $(11,12$, 18). However, the lifestyles of most people today are more sedentary than active.

Increasing evidence is indicating that cancer survivors can and should engage in physical activity as the efficacy and safety of interventions commenced both during and following cancer treatment have been proven (19-23). Adherence to healthy lifestyle behaviors such as being physically active plays a critical role in cancer prevention as it modifies breast cancer risk in postmenopausal women $(24,25)$. Breast cancer survivors who adhered to the current physical activity guidelines of 150 minutes/week of moderate-level activity, when compared with those who had low activity, are associated with significantly lower risk of death (RR/HR from 0.58 to 0.71 ) (26); and no activity $(\mathrm{RR} / \mathrm{HR}=0.36)$ (27). After a breast cancer diagnosis, a $40 \%$ $-50 \%$ lower risks of mortality has been associated with about 2 to 3 hours of moderate-intensity activity $(18,28)$, whilst another study indicated a duration of 3 to 5 hours per week. The evidence is strong that exercise before and after breast cancer diagnosis is inversely associated with the risk of recurrence and death (29). Controlling cancer via lifestyle factor such as adopting an active lifestyle is becoming particularly essential in cancer survivor populations.

\section{The recommended PA for general and cancer population}

The general exercise recommendation for people undertaking or having completed cancer treatment is low to moderate intensity, regular frequency ( 3 to 5 times per week) for at least 30 minutes per session $(21,30)$. This is consistent with recommendations for the general adult population (31). The American College of Sports Medicine (ACSM) recommends that healthy adults (32) and cancer survivors (33) perform a minimum of 30-min moderateintensity exercise on 5 days/week, for health promotion, whilst the World Cancer Research Fund (WCRF) and the American Institute for Cancer Research (AICR) advocate 
a higher dosage to specifically reduce cancer risk: $60 \mathrm{~min}$ of moderate-intensity or $30 \mathrm{~min}$ of vigorous-intensity exercise, daily (34).

\section{Physical activity for colon cancer}

There is convincing evidence that links physical activity with colon cancer. Evidence-based studies had proposed several mechanisms for the role of physical activity in reducing colon cancer risk which includes reduced insulin resistance and hyperinsulinemia, anti-inflammatory action, direct immune action, decreased intestinal transit time or higher vitamin D levels (35). A cohort of 573 women diagnosed with stages I-III colorectal cancer who participated in the Nurses' Health Study, reported women who are most physically active experienced $61 \%$ reduced colorectal cancer-specific mortality and $57 \%$ reduced overall mortality compared to inactive women (36). A meta-analysis conducted in 2009 on physical activity and colon cancer reported an overall risk reduction of approximately $24 \%$ (37) for both men and women.

\section{Physical activity for breast cancer}

There are increasing published data to date to show that physical activity has an important preventive role in breast cancer risk. A recent meta-analysis concluded that physical activity before pre-diagnosis reduced all-cause mortality by $18 \%$ and physical activity post-diagnosis reduced breast cancer deaths by $24 \%$, all-cause mortality by $41 \%$ and disease recurrence by $24 \%$ (38). Pronk et al (39) suggested that breast cancer risk was lower for women who spent shorter period on occupational sitting time and for post-menopausal women who exercise at or above the recommended physical activity level which is 30 minutes a day for three to five days at moderate-level of intensity. However, our study showed that most survivors are engaged in predominantly low-moderate physical activity (40).

\section{Physical inactivity during cancer survivorship}

Many cancer survivors are not pursuing healthy lifestyle. Despite the known benefits of exercise, only a few older adults reported performing regular exercise (41). A large study by American cancer Society found that only 30 percent to 47 percent $(n=9105)$ met the recommendation for physical activity (42). Today, sedentary behavior has been identified as one of the leading preventable causes of death (43). With increasing cancer burden, the challenge in the global cancer control is to improve understanding between the modifiable determinants of PA and to translate this knowledge into practical actions for a general public health. Therefore, researchers should not be focusing on just physical activity engagement, but also on physical inactivity or sedentary behavior which is now an independent factor regardless of whether women fulfill the recommended guidelines $(26,27)$.

\section{Specific Benefits of Physical Activity intervention}

Research evidence showed that physical activity during and after completion of treatment have resulted in better quality of life (44-46) and even improves fatigue body esteem and mood $(47,48)$. Epidemiologic studies suggest benefits of physical activity in tackling obesity, a known cancer risk factor, with a strong inverse relationship for breast cancer, especially among post-menopausal women (49). Nevertheless, physical activity engagement is beneficial for both pre-menopausal and post-menopausal women, whereby a $30 \%$ to $40 \%$ reduction in risk of developing breast cancer is postulated when compared with sedentary women (50).

Research evidence suggests that changes in activity from pre to post-diagnosis influences survival. Thus, intervention to increase an uptake of physical activity engagement post cancer is beneficial and therapeutic during the survivorship period. Survivors with a reduction of moderate-level physical activity by an hour or more per week have a risk of death up to four-fold (27). Among women with breast cancer, and compared to those who were inactive before and after diagnosis, those who increased their activity by about 60 minutes/week or more of moderate-level activity, halved their risk of breast-cancer death, as well as all-cause mortality, compared with those who had no change.

Overall, outcomes from physical activity interventions implemented during cancer survivorship periods suggest a much better adjustment to illness. Potential benefits in health promotion such as cardio-respiratory fitness; muscle mass and bone health; immune function; strength and flexibility; body image; self-esteem and mood. At least three prospective cohort studies on cancer survival have presented evidence of a significant relationship between increased physical activities and reduce mortality (26-28). More than 70 published experimental trials on physical activity for cancer survivors have shown that increased physical activity reduces mortality and the evidence is strongest for breast and colorectal cancers $(19,20,31)$ and prostate cancers (51). A large-scale randomized control trial with colorectal survivor via telephone sessions to enable symptom management, psychosocial and lifestyle support, showed promising results which included better quality of life; better diet uptake, and a reduced sedentary behavior (52). Regular, sufficient physical exercise apart from weight maintenance, diet and emotional strategies that may improve wellbeing, quality of life have the potential to reduce the risk of cancer recurrence (53).

\section{Future direction - Cancer survivorship research and practices}

There is a need to improve awareness of the needs of adopting low-risk lifestyle changes for cancer survivors and to recognize survivorship needs. Opportunities exist for occupational therapists, oncologists and primary care physicians to collaborate and to promote lifestyle changes 
(research and clinical practice) to improve the length and quality of life of their patients.

\section{Theory-driven research studies}

Theoretically driven studies, eg the use of social cognitive theory implicating its central tenet variables such as like attitudes and efficacy, help explain the reason for a successful behavior. More theory driven interventions should be used in physical activity behavior-change study. These approaches need to be incorporated into routine clinical care (54-56). Theory-led studies can inform the design of interventions to ensure how best to promote positive attitudes towards healthy behavior and thus enabling long-term behavioral change. Future work needs to assess more thoroughly what constitutes optimal exercise prescriptions, including the mode of delivery, cost effectiveness, frequency, duration, intensity and type, and how individual characteristics (eg. age, cancer type, treatment, presence of specific symptoms) affect this prescription (21). Also, research to find out the optimal period of utilizing these 'teachable moments' are imperative for a successful healthy behavioral lifestyle changes, as well as more rigorous designs which address methodological limitations (57). Occupational therapy studies contribute to lifestyle research to improve the understanding of lifestyle characteristics (eg. activity engagement and coping behaviors) and its relationships to health promotion and disease prevention (58). A recent systematic review (four primary prevention and five tertiary prevention trials) concluded small to moderate effect on improving concentrations of several blood biomarkers implicated in breast and colon cancer pathways (59). More studies are needed explaining the role of physical activity and cancer etiology (primary prevention) and also cancer prognosis (tertiary prevention).

\section{Evidence based clinical practices}

In particular, clinicians need to capture and optimize the period(s) of 'teachable moments' for the promotion and the adoption of low-risk lifestyle intervention in cancer care. Along with research evidence, behavioral strategies (such as counseling, coaching, motivational interviewing, goal setting, action planning) across a range of settings during this cancer survivorship period are required to propel cancer survivors to redesign their lifestyle. Specifically for physical activity as a modifiable cancer control factor - the adoption of physical activity as a key index to a healthy lifestyle behaviors must be supported and facilitated.

\section{Conclusion}

In conclusion, to quote the pancreatic cancer patient cited above: When persuaded by his wife to engage in more physical activity, he defended and debated with the analogy that the huge healthy oak tree outside his garden is and has been 'sedentary' for decades, but yet, it remains strong and healthy. Most people find it easier to be sedentary than to be active, and thus, the momentum to fight inertia and inactivity does require a strong motive and does need to be supported and reinforced. More health organizational effort is needed if we are to target towards getting cancer survivors to self manage a more active lifestyle. These efforts need organizational commitment, policy commitments, resources and facilities to ensure the Union International for Cancer Control (UICC)'s agenda can be achieved. Lastly, with a steep rise of cancer patients surviving more than five years beyond diagnosis, health systems throughout the world are challenged to expand their focus from acute care to managing this long-term health consequences of cancer. Consolidated, proactive effort for low-risk behaviors amongst cancer survivors must be carefully planned and implemented objective for cancer survivorship. More effort is needed to get cancer survivors to self manage an active lifestyle, and teachable moments must be optimize in order to gain effective engagement and adoption of healthy behaviors. These efforts must be supported by organizational commitment, resources and facilities to ensure this target of cancer control can be delivered to the increasing rise of cancer survivors.

\section{References}

1. Hewitt, M., \& Ganz, P. A. (2006). From cancer patient to cancer survivor - Lost in transition: An american society of clinical oncology and institute of medicine symposium. Washington, D.C.: Institute of Medicine and National Research Council of the National Academies. (T. N. A. Press o. Document Number)

2. Bower, J., Meyerowitz, B., Desmond, K., Bernaards, C., Rowland, J., \& Ganz, P. (2005). Perceptions of positive meaning and vulnerability following breast cancer: predictors and outcomes among long-term breast cancer survivors. Ann Behav Med, 29(3), 236-245.

3. Jemal, A., Murray, T., Ward, E., Samuels, A., Tiwari, R., Ghafoor, A., et al. (2005). Cancer statistics. CA Cancer J Clin, 55, 10-30.

4. Loh, S. Y., \& CH Yip. (2006). Breast cancer as a chronic illness: Implication for Rehabilitation and Medical Education. Jornal of University Malaya Medical Centre, 9(2), 3-11.

5. Fallowfield, L. (2004). Evolution of breast cancer treatments: current options and quality-of-life considerations. European Journal of Oncology Nursing (2004) 8S, S75-S82.

6. Anand, P., Kunnumakara, A. B., Sundaram, C., Harikumar, K. B., Tharakan, S. T., Lai, O. S., et al. (2008). Cancer is a preventable disease that requires major lifestyle changes. Pharmaceutical Research 2008; 25(9): 2097-2116.

7. Wendy Demark-Wahnefried, Noreen M. Aziz, Julia H. Rowland, \& Bernardine M. Pinto. Riding the Crest of the Teachable Moment: Promoting Long-Term Health After the Diagnosis of Cancer Journal of Clinical Oncology 2005; 23(24 (August 20)): 5814-5830. 
8. McCarthy, A. M., \& Visvanathan, K. (2010). Breast cancer prognosis: weighing the evidence on weight and physical activity. Oncology, 24(4), 1-5.

9. World Health Organization. Fact sheet no. 297: Cancer. 2009 [Electronic Version]. Retrieved June 3 2009, from http://www.who.int/mediacentre/ factsheets/fs297/en/index.html.

10. Stuart, K., Brennan, B., French, J., Houssami, N., \& Boyages, J. Life after breast cancer. Australian Family Physician 2006; 35(April 2006): 177-258.

11. Eakin, E. G., Youlden, D. R., Baade, P. D., Lawler, S. P., Reeves, M. M., Heyworth, J. S., et al. (2006). Health Status of Long-term Cancer Survivors: Results from an Australian Population-Based Sample. Cancer Epidemiology Biomarkers \& Prevention, 15(10), 19691976.

12. Hawkes, A., Lynch, B., Youlden, D., Owen, N., \& Aitken, J. (2008). Health behaviors of Australian colorectal cancer survivors, compared with noncancer population controls. Supportive Care in Cancer, 16(10), 1097-1104.

13. Coory, M., Baade, P., Aitken, J., Smithers, M., McLeod, G., \& Ring, I. (2006). Trends for in situ and Invasive Melanoma in Queensland, Australia, 1982-2002 Cancer Causes and Control, 17(1), 21-27.

14. Loh, S. Y., Packer, T., Yip, C. H., \& Low, W. Y. (2007). Perceived Barriers to Self Management in Malaysian Women. Asia Pacific Journal of Public Health, 19(3).

15. Speck, R., Courneya, K. S., Masse, L., Duval, S., \& Schmitz, K. An update of controlled physical activity trials in cancer survivors: a systematic review and meta-analysis. Journal of Cancer Survivorship 2010; 4(2): 87-100.

16. Velthuis, M. J., Agasi-Idenburg, S. C., Aufdemkampe, G., \& Wittink, H. M. The Effect of Physical Exercise on Cancer-related Fatigue during Cancer Treatment: a Meta-analysis of Randomised Controlled Trials. Clinical oncology (Royal College of Radiologists (Great Britain)) 2010; 22(3): 208-221.

17. Wiskemann, J., \& Huber, G. Physical exercise as adjuvant therapy for patients undergoing hematopoietic stem cell transplantation. Bone Marrow Transplant 2007; 41(4): 321-329.

18. Holmes, M. D., Chen, W. Y., Feskanich, D., Kroenke, C. H., \& Colditz, G. A. (2005). Physical Activity and Survival After Breast Cancer Diagnosis. JAMA, 293(20), 2479-2486.

19. Courney, K. S. (2003). Exercise in cancer survivors: an overview of research. Med Sci Sports Exerc, 35(11), $1846-1852$.

20. Galvao, D. A., \& Newton, R. U. (2005). Review of exercise intervention studies in cancer patients. J Clin Oncol, 23(4), 899 - 909.

21. Hayes, S. C., Spence, R. R., GalvÃfo, D. A., \& Newtonc, R. U. (2009). Australian Association for Exercise and Sport Science position stand: Optimising cancer outcomes through exercise. Journal of science and medicine in sport / Sports Medicine Australia, 12(4), 428-434.
22. Monninkhof, E. M., Elias, S. G., Vlems, F. A., van der Tweel, I., Schuit, A. J., Voskuil, D. W., et al. (2007). Physical activity and breast cancer: a systematic review. Epidemiology, 18(1), 137-157.

23. Stevinson, Clare, Lawlor, Debbie, A., Fox, \& Kenneth, R. Exercise interventions for cancer. Dordrecht, PAYSBAS: Springer 2004; (Vol. 15).

24. Carpenter, C. L., Ross, R. K., Paganini-Hill, A., \& Bernstein, L. (2003). Effect of family history, obesity and exercise on breast cancer risk among postmenopausal women. INTERNATIONAL JOURNAL OF CANCER, 106(1), 96-102.

25. Gramling, R., Lash, T., Rothman, K., Cabral, H., Silliman, R., Roberts, M., et al. (2010). Family history of later-onset breast cancer, breast healthy behavior and invasive breast cancer among postmenopausal women: a cohort study. Breast Cancer Research, 12(5), R82.

26. Kroenke, C., Chen, B., Kawachi, I., Colditz, G., \& Holmes, M. (2004). Functional Impact of Breast Cancer by Age at Diagnosis. JOURNAL OF CLINICAL ONCOLOGY, 22(10 (May 15)), 1849-1856.

27. Irwin, M. L., Smith, A. W., McTiernan, A., BallardBarbash, R., Cronin, K., Gilliland, F. D., et al. (2008). Influence of pre- and postdiagnosis physical activity on mortality in breast cancer survivors: The health, eating, activity and lifestyle study. Journal of Clinical Oncology, 26(24), 3958-3964.

28. Holick, C. N., Newcomb, P. A., Trentham-Dietz, A., Titus-Ernstoff, L., Bersch, A. J., Stampfer, M. J., et al. (2008). Physical Activity and Survival after Diagnosis of Invasive Breast Cancer. Cancer Epidemiology Biomarkers \& Prevention, 17(2), 379-386.

29. Verloop, J., Rookus, M. A., van der Kooy, K., \& van Leeuwen, F. E. Physical Activity and Breast Cancer Risk in Women Aged 20-54 Years. Journal of the National Cancer Institute 2000; 92(2): 128-135.

30. Ainsworth, B. E. (2009). How do I measure physical activity in my patients? Questionnaires and objective methods. British Journal of Sports Medicine 2009; 43(1): 6-9.

31. Courneya, K. S., Mackey, J. R., \& McKenzie, D. C. (2002). Exercise for breast cancer survivors: research evidence and clinical guidelines. 30, 33-42.

32. Haskell, W. L., Lee, I. M., Pate, R. R., Powell, K. E., Blair, S. N., Franklin, B. A., et al. (2007). Physical activity and public health. Updated recommendations for adults from the American College of Sports Medicine and the American Heart Association. Circulation, 116, 1081 - 1093.

33. Schmitz KH, Courneya KS, Matthews C, DemarkWahnefried W, Galvao DA, BM, P., et al. American College of Sports Medicine roundtable on exercise guidelines for cancer survivors. . Med Sci Sport Exerc 2010; 42: 1409-1426

34. World Cancer Research Fund, \& American Institute for Cancer Research. The second expert report: food, nutrition, physical activity and the prevention of cancer: a global perspective. 2007 [Electronic Version], 
35. Wolin, K. Y., Lee, I. M., Colditz, G. A., Glynn, R. J., Fuchs, C., \& Giovannucci, E. Leisure-time physical activity patterns and risk of colon cancer in women. INTERNATIONAL JOURNAL OF CANCER 2007; 121(12): 2776-2781.

36. Meyerhardt, J. A., Giovannucci, E. L., Holmes, M. D., Chan, A. T., Chan, J. A., Colditz, G. A., et al. (2006). Physical Activity and Survival After Colorectal Cancer Diagnosis. Journal of Clinical Oncology, 24(22), 35273534.

37. Wolin, K. Y., Yan, Y., Colditz, G. A., \& Lee, I. M. Physical activity and colon cancer prevention: a meta-analysis. British Journal of Cancer 2009; 100(4): 611-616.

38. Ibrahim, E., \& Al-Homaidh, A. (2011). Physical activity and survival after breast cancer diagnosis: metaanalysis of published studies. Medical Oncology, 28(3), 753-765.

39. Pronk, A., Ji, B. T., Shu, X. O., Chow, W. H., Xue, S., Yang, G., et al. Physical activity and breast cancer risk in Chinese women. Br J Cancer 2011.

40. SY, L., SL, C., \& SY, L. Barriers to exercise - Perspectives from multiethnic Cancer survivors. JUMMEC 2011; 12(1).

41. Hirvensalo, M., Lampinen, P., \& Rantanen, T. (1998). Physical exercise in old age: an eight-year followup study on involvement, motives and obstacles among persons aged 65-84 year. Journal of Aging and Physical Activity, 6, 157-168.

42. Blanchard, C., Courneya, K., \& Stein, K. (2008). American Cancer Society's SCS-II. Cancer survivors'adherence to lifestyle behavior recommendations and associations with health-related quality of life. J Clin Oncol 2008: 26(13); 2198-2204.

43. Mokdad, A. H., Marks, J. S., Stroup, D. F., \& Gerberding, J. L. (2004). Actual Causes of Death in the United States, 2000. JAMA, 291(10), 1238-1245.

44. McNeely, M., Campbell, K., Rowe, B., Klassen, T., Mackey, J., \& Courneya, K. (2006). Effects of exercise on breast cancer patients and survivors: a systematic review and meta-analysis. Med. Assoc. J., 175(1), 3441.

45. Milne, H. M., Gordon, S., Guilfoyle, A., Wallman, K. E., \& Courneya, K. S. (2007). Association between physical activity and quality of life among Western Australian breast cancer survivors. Psycho-Oncology, 16(12), 1059-1068.

46. Mock, V., Frangakis, C., Davidson, N. E., Ropka, M. E., Pickett, M., Poniatowski, B., et al. (2005). Exercise manages fatigue during breast cancer treatment: $A$ randomized controlled trial. Psycho-Oncology, 14(6), 464-477.
47. Pinto, B. M., \& Maruyama, N. C. (1999). Exercise in the rehabilitation of breast cancer survivors. PsychoOncology, 8(3), 191-206.

48. Pinto, B. M., \& Trunzo, J. J. (2004). Body Esteem and Mood Among Sedentary and Active Breast Cancer Survivors. Mayo Clinic Proceedings, 79(2), 181-186.

49. Monninkhof EM, Elias SG, Vlems FA, \& al., e. (2007). Physical activity and breast cancer: a systematic review. . Epidemiology 18, 137-157.

50. Thune, I., \& Furberg, A.-S. Physical activity and cancer risk: dose-response and cancer, all sites and site-specific. Medicine \& Science in Sports \& Exercise 2001; 33(6): S530-S550.

51. Segal, R. J., Reid, R. D., Courneya, K. S., Sigal, R. J., Kenny, G. P., Prud'Homme, D. G., et al. Randomized Controlled Trial of Resistance or Aerobic Exercise in Men Receiving Radiation Therapy for Prostate Cancer. Journal of Clinical Oncology 2009; 27(3): 344-351.

52. Hawkes, A., Gollschewski, S., Lynch, B., \& Chambers, S. (2009). A telephone-delivered lifestyle intervention for colorectal cancer survivors 'CanChange': a pilot study. Psycho-Oncology, 18(4), 449-455.

53. Demark-Wahnefried, W., Pinto, B., \& Gritz, E. (2006). Promoting Health and Physical Function Among Cancer Survivors: Potential for Prevention and Questions That Remain. J Clin Oncol, 24(32), 51255131.

54. Courneya, K. S., \& McAuley, E. (1996). Understanding Intentions to Exercise Following a Structured Exercise Program: An Attributional Perspective1. Journal of Applied Social Psychology, 26(8), 670-685.

55. Hausenblas, H. A., Carron, A. V., \& Mack, D. E. (1997). Application of the theories of reasoned action and planned behavior to exercise behavior: a metaanalysis. Journal of Sports \& Exercise Psychology, 19(1), 36-51.

56. Vallance, J. K., Courneya, K. S., Taylor, L. M., Plotnikoff, R. C., \& Mackey, J. R. Development and Evaluation of a Theory-Based Physical Activity Guidebook for Breast Cancer Survivors. Health Education \& Behavior 2008; 35(2): 174-189.

57. Rosalind, R. S., Kristiann, C. H., \& Wendy, J. B. Exercise and cancer rehabilitation: A systematic review. Cancer Treatment Reviews 2010; 36 : 185-194.

58. Christensen, C., \& Baum, M. (Eds.). (2005). Occupational Therapy: performance, participation and wellbeing. Thorofare, NJ: SLACK.

59. BM. Winzer, DC. Whiteman, MM. Reeves, \& JD. Paratz. (2011). Physical activity and cancer prevention: a systematic review of clinical trials. Cancer Causes Control 2011; 22: 811-826. 